\title{
The frequency of microscopic and focal active colitis in patients with irritable bowel syndrome
}

\author{
Kamil Ozdil', Abdurrahman Sahin ${ }^{1 *}$, Turan Calhan', Resul Kahraman', Adil Nigdelioglu', Umit Akyuz and \\ Hacı M Sokmen ${ }^{1}$
}

\begin{abstract}
Background: Irritable bowel syndrome (IBS) is a chronic functional bowel disorder. The frequency of microscopic colitis and focal active colitis in the colonic mucosa has been investigated in IBS patients.

Methods: Between June 2007 and September 2010, 378 patients (between 16 and 84 years) were recruited prospectively. Of these 378 patients, 226 patients were diagnosed with IBS using the Rome III criteria. 152 control patients were also enrolled who were undergoing colonoscopy for colorectal cancer screening or investigation of anemia. Histopathological abnormalities identified during colonoscopy were compared between the IBS and control groups.

Results: The average age of the IBS group was $46.13 \pm 14.16$ years and and the average age of the control group was $57.01 \pm 13.07$ years. The prevalence of microscopic colitis (MC) in the diarrhea predominant and the mixed subgroup of IBS patients was 4.32\% (7/162) whereas in all IBS patients, the prevalence was 3.09\% (7/226). MC was not found in the 152 control cases, $(p=0.045)$. Lymphocytic colitis was seen in 7 IBS patients, with 1 case in the mixed group and 6 cases in the diarrhea group and there was a significant difference in the frequency of lymphocytic colitis between the IBS subgroups $(p<0.01)$. Focal active colitis was found in $6.6 \%(15 / 226)$ of the IBS patients and in none of the controls $(p<0.01)$, and there was no differences between IBS subtypes.

Conclusion: Microscopic colitis was more often found in the diarrhea predominant/mixed subgroups of IBS patients and in patients who were older women. In patients who are older woman with non-constipated IBS, it may be reasonable to perform a biopsy to screen for microscopic colitis. Focal active colitis was significantly increased in patients with IBS compared to controls.
\end{abstract}

Keywords: irritable bowel syndrome, microscopic colitis, focal active colitis

\section{Background}

Irritable bowel syndrome (IBS) is a functional bowel disorder of unknown etiology without a curative treatment. In addition to abdominal discomfort and pain, relief from discomfort upon defecation and/or abdominal pain is associated with a change in the frequency of defecation and/or in the form of the feces [1]. The prevalence of IBS varies in different populations. The prevalence of IBS in Turkey was found 7.4-19.1\% with female percentage between $64 \%$ and $69 \%$ [2,3]. Similar rates have been reported in the USA and Europe and range between

\footnotetext{
* Correspondence: arahmansmd@hotmail.com

'Department of Gastroenterology, Umraniye Training and Research Hospital, Adem Yavuz street No:1, Umraniye, Postal code:34766, Istanbul, TURKEY Full list of author information is available at the end of the article
}

$6.2 \%$ and $25 \%[4,5]$. Although the specific location and the pattern of symptoms varies among different functional gastrointestinal diseases, there are also many common characteristics [6]. A small percentage of patients with IBS are referred to outpatient gastroenterology clinics.

In 1980, microscopic colitis (MC) was defined as having symptoms of watery diarrhea and specific histological characteristics when the colonic mucosa is macroscopically normal or near normal [7]. Currently, $\mathrm{MC}$ is divided into two subtypes- collagenous colitis (CC) involving chronic mucosal inflammation and a wide subepithelial band and lymphocytic colitis (LC) involving chronic mucosal inflammation and no subepithelial band. In 1976, Lindstrom showed for the first

C Biomed Central

(c) 2011 Ozdil et al; licensee BioMed Central Ltd. This is an Open Access article distributed under the terms of the Creative Commons Attribution License (http://creativecommons.org/licenses/by/2.0), which permits unrestricted use, distribution, and reproduction in any medium, provided the original work is properly cited. 
time that collagen deposits accumulated as a wide subepithelial band in the rectum and colon in patients with persistent watery diarrhea of unknown cause [8]. Some experts claim that LC is an early phase of CC [9-11]. In Europe, the annual incidence of $\mathrm{CC}$ is $0.6-2.3 / 100000$ and the prevalence is $10-15.7 / 100000$ whereas the annual incidence of LC is $3.1 / 100000$ and the prevalence is $14.4 / 100000$ [12-16]. MC and IBS have similar symptoms. MC not only leads to diarrhea but also causes constipation. Constipation may be short-term or chronic $[17,18]$.

Focal active colitis (FAC) is characterized by focal crypt damage caused by neutrophils and may be associated with infections, ischemia, Crohn's disease, partially-treated ulcerative colitis and IBS [19]. It may consist of one focus that can be detected in a single biopsy, or multiple foci. Since focal inflammation is a feature of Crohn's disease, studies of FAC have examined whether it precedes the subsequent development or diagnosis of Crohn's disease. In two studies of adult patients with FAC, it was observed that very few developed Crohn's disease $[19,20]$. However, in a group of pediatric patients with FAC, a higher proportion (27.6\%) went on to develop Crohn's disease [21].

The purpose of this study was to determine histopathologically the frequency of underlying organic causes of IBS, including MC and FAC, in macroscopically normal colonic mucosa.

\section{Methods}

Between June 2007 and September 2010, 378 patients (between 16 and 84 years) were recruited into the study prospectively. Two hundred and twenty six of these patients were diagnosed with IBS using the Rome III criteria and had no alarm symptoms, no chronic disease history and had macroscopically normal colonoscopy/ upper gastrointestinal system endoscopic findings. There were 152 control patients who had no history of chronic disease or drug use, who were undergoing colonoscopy for reasons not related to IBS (familial colorectal cancer screening or investigation of anemia) and who had macroscopically normal colonic mucosa.

Patients with IBS were divided into 3 subgroups according to the Rome III criteria. Patients with hard or lumpy stools $\geq 25 \%$ and loose (mushy) or watery stools $<25 \%$ of bowel movements the constipation-predominant group (IBS-C). Patients with loose (mushy) or watery stools $\geq 25 \%$ and hard or lumpy stools $<25 \%$ of bowel movements as the diarrhea-predominant group (IBS-D). Patients expressing hard or lumpy stools $\geq 25 \%$ and loose (mushy) or watery stools $\geq 25 \%$ of bowel movements were defined as the mixed group (IBS-M) [22-24]. The presence of alarm symptoms (Table 1)[25], malignancy of the gastrointestinal system, inflammatory
Table 1 Alarm features considered potentially relevant in the diagnosis of organic disease as opposed to Irritable Bowel Syndrome

Rectal bleeding

Family history of colon cancer, inflammatory bowel disease, or celiac disease

Night-time symptoms (awakening the patient from sleep)

Weight loss

Signs of anemia

Abdominal mass

bowel disease or other chronic diseases in other systems, metabolic or endocrine diseases (diabetes, hyperthyroidism and hypothyroidism, adrenocortical diseases), heart insufficiency, chronic obstructive pulmonary disease, hepatic cirrhosis, chronic renal insufficiency, severe depression or a history of persistent use of medications and tobocco were excluded from the analysis. All patients were examined using microscopic evaluation of the stool, a stool occult blood test, digestive stool analysis, hemogram, erythrocyte sedimentation rate, blood glucose, urea, creatinine, liver tests, thyroid hormones (free T4, TSH), anti-endomisium IgA and anti-gliadin IgG antibodies with upper gastrointestinal endoscopy (for excluding Celiac disease and other upper GIS disorders), abdominal ultrasonography and colonoscopy. During colonoscopy, terminal ileum was intubated and then two biopsy samples were taken from the cecum, ascending, transverse, descending, sigmoid colon and rectum.

Biopsy specimens were sent to the pathology laboratory in $10 \%$ formol solution. All biopsy samples were evaluated by two pathologists who specialized in the gastrointestinal system. Paraffin blocks were cut into 5 $\mu \mathrm{m}$ thick sections and stained with hematoxylin-eosin (H\&E) and Gomori's trichrome stain. A diagnosis of lymphocytic colitis required an increase in intraepithelial lymphocytes to more than 15 lymphocytes/100 epithelial cells, surface epithelial damage with increased lamina propria, plasma cells and absent or minimal crypt architectural disruption. For a diagnosis of collagenous colitis, an increase/irregularity in subepithelial collagen (> $10 \mu \mathrm{m})$ that typically trapped superficial capillaries was required as well as the other inflammatory changes seen in lymphocytic colitis [12]. Focal active colitis is the term used to describe focal neutrophilic infiltration of colonic crypts. It may consist of one focus in a single biopsy, or multiple foci [19].

The study protocol was approved by our Institutional (Umraniye Training and Research Hospital) Research Ethics Committee and informed consent was obtained from each subject.

Statistical analysis was performed using NCSS (Number Cruncher Statistical System) 2007 \& PASS (Power 
Analysis and Sample Size) 2008 Statistical Software (Utah, USA), SPSS version 11.0 and Microsoft Excel. Statistical comparisons of findings between the IBS and control groups were performed by $\chi^{2}$ or Fisher's exact test. Logistic regression was used to adjust for differences in age and gender between groups. A p $<0.05$ was considered statistically significant.

\section{Results}

A total of 378 patients were included in the study, 193 were female $(51.1 \%)$, and the mean age of was $50.51 \pm$ 14.72 for all patients (range 16-84). Two hundred and twenty six patients were in the IBS groups and their average age was $46.13 \pm 14.16,125$ (55.3\%) were female and $101(44.7 \%)$ were male. In the control group of 152 patients, 84 were males (55.3\%), 68 were females $(44.7 \%)$ and the average age was $57.01 \pm 13.07$ years. There was a statistically significant difference in the age distributions of the IBS and control groups $(P<0.01)$. Additionally, a statistically significant difference in the gender distribution between the two groups was present $(\mathrm{p}=$ $0.044)$. Lymphocytic colitis was present in $3.1 \%(7 / 226)$ of IBS patients and $0 \%$ of controls $(\mathrm{p}<0.05)$ (Table 2$)$. Collagenous colitis was found neither patient group, nor control group.

The IBS group of 226 patients was divided into 3 subgroups. 64 patients $(28.3 \%)$ were in IBS-C, 90 patients (39.8\%) were in IBS-M and 72 patients $(31.9 \%)$ were in IBS-D. Serum biochemical tests, hemoglobin values and stool tests and macroscopic colonoscopic examinations were normal in all patients. MC was present in $4.32 \%$ (7/126) of non-constipated patients (diarrhea predominant and mixed) and in $3.1 \%$ of all IBS patients (7/226). However, lymphocytic colitis differed between non-constipated IBS group (IBS-D and IBS-M) and constipated IBS patients $(\mathrm{p}<0.01)$. No lymphocytic colitis was seen in the constipation dominant group, only 1 case $(1.1 \%)$ was seen in the mixed group and 6 cases (8.3\%) were seen in the diarrhea dominant group (Table 3 and Table 4).

Focal active colitis was found in $6.6 \%(15 / 226)$ of IBS patients and in none of the controls $(\mathrm{p}<0.01)$. There was no significant difference among the incidence of

Table 2 Demographic and pathological data of IBS and control patients

\begin{tabular}{|c|c|c|c|}
\hline & IBS $(n=226)$ & Control $(n=152)$ & $p$ \\
\hline${ }^{\mathrm{a} A g e ;}$ Mean \pm SD & $46.13 \pm 14.16$ & $57.01 \pm 1 ., 07$ & $0.001^{* *}$ \\
\hline${ }^{\mathrm{b}}$ Gender (female, \%) & $125(55.3 \%)$ & $68(44.7 \%)$ & $0.044^{*}$ \\
\hline bymphoscytic colitis & $7(3.1 \%)$ & $0(0 \%)$ & $0.045^{*}$ \\
\hline${ }^{\mathrm{b}}$ Focal active colitis & $15(6.6 \%)$ & $0(0 \%)$ & $0.001^{* *}$ \\
\hline
\end{tabular}

focal active colitis according to IBS subtype ( $\mathrm{p}>0.05$ ), although there was a higher incidence in the mixed group. Of the patients with FAC, $1.6 \%(1 / 64)$ were in the constipation predominant group, $11.1 \%(10 / 90)$ were in the alternate group and $5.6 \%(4 / 72)$ were in the diarrhea predominant group (Table 2).

\section{Discussion}

IBS is a public health problem since it is widely seen and does not have a cure [26]. Some experts claim that LC is a precursor to CC [9-11]. A previously published study evaluated 89 patients suspected to have IBS and 59 controls using flexible sigmoidoscopy and rectal biopsy. These authors reported that no IBS patients or controls had macroscopic or microscopic findings that resulted in a change in diagnosis. Specifically, the authors identified no patients or controls with microscopic colitis. But according to recently published a study by Kao et al. in which a total of 547 cases of $\mathrm{MC}$ were examined, $\mathrm{MC}$ had a higher occurrence in IBS than in controls $(\mathrm{P}<0.001)$ [27]. Conditions such as celiac disease, IBS, and thyroid disease were found to be related to MC. Furthermore, neither an increased risk of colorectal cancer nor IBD was associated with MC [27]. Chey et al. found that colonoscopy and colonic mucosal biopsies were able to identify an alternative diagnosis in $1.9 \%(9 / 466)$ of non-constipated IBS patients [28]. Of these nine patients, seven had microscopic colitis, one had Crohn's disease, and one had ulcerative colitis. The overall prevalence of microscopic colitis was found to be $1.5 \%$ in a large cohort of non-constipated IBS patients. In a subgroup analysis of IBS patients over the age of 45 , the prevalence of microscopic colitis was $2.3 \%(4 / 171)$. In our study we found that all subjects with microscopic colitis were at least 49 years old and microscopic colitis was seen in 4.32\% (7/126) of nonconstipated IBS patients and in 3.1\% of all IBS patients (7/ 226). All MC patients were over 45 years old and the average age was $62 \pm 8$. Limsui et al. found that $56 \%$ of the 131 patients diagnosed with microscopic colitis fulfilled the Rome III criteria for IBS and that 33\% had been diagnosed with IBS before receiving the diagnosis of microscopic colitis. Therefore, patients with suspected diarrheapredominant IBS should undergo biopsies of the colon to investigate possible microscopic colitis if symptoms are not well controlled by anti-diarrheal therapy [29].

A retrospective study found that $11 \%$ (43/376) of patients with LC and 18\% (30/171) of patients with CC had been diagnosed with IBS before receiving the diagnosis of MC [27]. In two large studies of patients with $\mathrm{MC}$, the mean age of diagnosis was found to be in the seventh decade [27,29]. A recent review on this topic suggested that between $18 \%$ and $34 \%$ of patients with collagenous colitis may not be identified if only rectosigmoid biopsies are obtained [30]. 
Table 3 Demographic and pathological data of IBS subgroups

\begin{tabular}{|c|c|c|c|c|}
\hline & \multicolumn{3}{|c|}{ IBS subgroups } & \multirow[t]{2}{*}{1} \\
\hline & IBS-C $(n=64)$ & IBS-M $(n=90)$ & IBS-D $(n=72)$ & \\
\hline${ }^{\alpha}$ Age (Mean \pm SD) & $43.54 \pm 13.17$ & $47.53 \pm 13.54$ & $46.68 \pm 15.57$ & 0.211 \\
\hline${ }^{\mathrm{b}}$ Gender (female,\%) & $43(67.2 \%)$ & $45(50 \%)$ & $37(51.4 \%)$ & 0.077 \\
\hline${ }^{\beta}$ Lymphochytic colitis $n(\%)$ & $0(0 \%)$ & $1(1.1 \%)$ & $6(8.3 \%)$ & $0.007^{* *}$ \\
\hline${ }^{\beta}$ Focal active colitis $n(\%)$ & $1(1.6 \%)$ & $10(11.1 \%)$ & $4(5.6 \%)$ & 0.058 \\
\hline
\end{tabular}

IBS has 3 subtypes according to its clinical course (constipation predominant, diarrhea predominant and mixed). IBS can be differentiated from MC only by histopathological investigation. Symptoms of MC are often attributed to diarrhea predominant IBS [31]. In view of this information, the present study explored if mucosal pathology, including MC, could be identified in IBS patients using microscopic evaluation, given that macroscopically, the colonic mucosa was normal.

Microscopic colitis is a rare disease [12-16]. However, Tuncer et al. reported that there is a $23.3 \%$ MC prevalence in IBS patients compared to a $5 \%$ prevalence in

Table 4 Demografic characteristics of patients with lymphocytic colitis and focal active colitis

\begin{tabular}{|c|c|c|c|}
\hline & Age & Gender & IBS Subtype \\
\hline Lymphocytic colitis & (Mean age: 60.5) & & \\
\hline Patient 1 & 49 & Female & IBS-D \\
\hline Patient 2 & 49 & Female & IBS-M \\
\hline Patient 3 & 56 & Female & IBS-D \\
\hline Patient 4 & 56 & Female & IBS-D \\
\hline Patient 5 & 69 & Female & IBS-D \\
\hline Patient 6 & 70 & Female & IBS-D \\
\hline Patient 7 & 75 & Female & $\mathrm{IBS}-\mathrm{D}$ \\
\hline Focal active colitis & (Mean age: 45.7) & & \\
\hline Patient 1 & 21 & Male & $\mathrm{IBS}-\mathrm{D}$ \\
\hline Patient 2 & 24 & Male & IBS-M \\
\hline Patient 3 & 30 & Female & IBS-D \\
\hline Patient 4 & 31 & Female & IBS-M \\
\hline Patient 5 & 32 & Male & IBS-M \\
\hline Patient 6 & 49 & Male & IBS-M \\
\hline Patient 7 & 50 & Male & IBS-D \\
\hline Patient 8 & 50 & Female & IBS-M \\
\hline Patient 9 & 51 & Female & IBS-M \\
\hline Patient 10 & 54 & Male & IBS-M \\
\hline Patient 11 & 54 & Female & IBS-M \\
\hline Patient 12 & 54 & Male & IBS-M \\
\hline Patient 13 & 60 & Female & IBS-C \\
\hline Patient 14 & 60 & Male & IBS-M \\
\hline Patient 15 & 66 & Female & IBS-D \\
\hline
\end{tabular}

IBS-C: Constipated predominant, IBS-D: Diarrhea predominant, IBS-M:Mixed controls [32]. According to a study by Olesen et al., MC was diagnosed in $10 \%$ of all Swedish patients (1018 patients) with non-bloody diarrhea referred for colonoscopy. In the subset of patients older than 70, the prevalence was almost 20\% [14]. Another study found that lymphocytic colitis was diagnosed in 199 cases. The female/male ratio was $2.4: 1$. The median age at diagnosis was 59 (range: 48-70) years. The most frequent symptoms were diarrhea (96\%), abdominal pain $(47 \%)$ and weight loss $(41 \%)$. The symptom course was chronic intermittent in $30 \%$ of patients, chronic continuous in $7 \%$, and single attack in $63 \%$. MC patients may have constipation and there may be an association between MC and chronic constipation. Chronic constipation was found in $43.39 \%$ of MC patients in the study performed by Barta et al. $[17,26]$. However, in our study, MC was not found in the constipation predominant IBS subgroup. According to the American College of Gastroenterology Task Force [25], "routine colonic imaging is not recommended in patients younger than 50 years of age with typical IBS symptoms and no alarm features. When colonoscopy is performed in patients with IBS-D, obtaining random biopsies should be considered to rule out microscopic colitis."

Focal active colitis is characterized by focal crypt damage caused by neutrophils and may be associated with infections, ischemia, Crohn's disease, partially-treated ulcerative colitis and IBS [19]. There are reports that there is an association between focal active colitis and oral sodium phosphate ingestion [33-36]. Driman et al. indicated that evidence is emerging that sodium phosphate is a commonly used oral laxative agent, causes aphthoid ulcers and/or FAC in the colon and rectum. FAC was present in 11 of 316 patients (3.5\%) who had biopsies but who were otherwise normal, as determined by endoscopic evaluation [33]. In a follow-up study by Xin et al., which consisted of 29 patients who were diagnosed with focal active colitis, the disease duration ranged from 4 months to 7 years with a mean of 4.2 years. Eight patients (27.6\%) developed Crohn's disease. Pediatric patients with focal active colitis have a much higher incidence of Crohn's disease than adults. Hence, 
it is important to document the presence of focal active colitis in pediatric patients [21]. In this study we found that $6.6 \%$ of IBS patients had focal active colitis (15/226) and this ratio is higher than that reported in previous studies. It may be eligible take a routine biopsy in female patients and in patients over 50 years old.

We acknowledge the limitation of the study is the difference between the groups in terms of age and gender. The percentage of women with IBS is $55.3 \%$. This percentage is close to the female:male ratio of previous studies from Turkey. The mean age of the control group was higher than the IBS patients. However, this situation was due to selection of asymptomatic patients screened for colorectal cancer and anemia.

\section{Conclusion}

Microscopic colitis can be identified in patients with diarrhea predominant IBS and in women of older age with IBS. It appears reasonable to test for microscopic colitis in those patients by performing a colonic biopsy. Focal active colitis was found to be more common than expected. Routine biopsy of normal colonic mucosa helps identify rare miscellaneous causes of colitis.

\section{Abbreviations}

CC: collagenous colitis; FAC: focal active colitis; IBS: irritable bowel syndrome; LC: Iymphocytic colitis; MC: microscopic colitis

\section{Author details}

'Department of Gastroenterology, Umraniye Training and Research Hospital, Adem Yavuz street No:1, Umraniye, Postal code:34766, Istanbul, TURKEY. ${ }^{2}$ Department of Gastroenterology, Fatih Sultan Mehmet Training and Research Hospital, Ataşehir, Postal code: 34770, Istanbul, TURKEY.

\section{Authors' contributions}

AS participated in coordination and drafted the manuscript. KO conceived of the study, and participated in its design and coordination and helped to draft the manuscript. TC and AN helped collecting the data of the patient. RK conceived of the study and participated in its design and coordination and helped to draft the manuscript. UA has contributed to statistic analysis and manuscript preparation. HMS has contributed to study design and has coordinated research team. All authors read and approved the final manuscript.

\section{Competing interests}

The authors declare that they have no competing interests.

Received: 17 April 2011 Accepted: 31 August 2011

Published: 31 August 2011

\section{References}

1. Thompson WG, Longstreth GF, Drossman DA, Heaton KW, Irvine EJ, MüllerLissner SA: Functional bowel disorders and functional abdominal pain. Gut 1999, 45(Suppl 2):I143-7.

2. Karaman N, Turkay C, Yonem O: Irritable bowel syndrome prevalence in city center of Sivas. Turk J Gastroenterology 2003, 14(2):128-31.

3. Celebi S, Acik Y, Deveci SE, Bahcecioglu IH, Ayar A, Demir A, Durukan P: Epidemiological features of irritable bowel syndrome in a Turkish urban society. Journal of gastroenterology and hepatology 2004, 19(7):738-43.

4. Hungin AP, Whorwell PJ, Tack J, Mearin F: The prevalence, patterns and impact of irritable bowel syndrome: an international survey of 40,000 subjects. Alimentary pharmacology \& therapeutics 2003, 17(5):643-50.
5. Jones R: Investigating lower bowel symptoms in general practice. BMJ 1992, 304(6841):1521-2.

6. Talley NJ, Spiller R: Irritable bowel syndrome: a little understood organic bowel disease? Lancet 2002, 360(9332):555-64.

7. Read NW, Krejs GJ, Read MG, Santa Ana CA, Morawski SG, Fordtran JS: Chronic diarrhea of unknown origin. Gastroenterology 1980, 78(2):264-71.

8. Lindstrom CG: 'Collagenous colitis' with watery diarrhoea-a new entity? Pathologia Europaea 1976, 11(1):87-9.

9. Bowling $T E$, Price AB, al-Adnani M, Fairclough PD, Menzies-Gow N, Silk DB: Interchange between collagenous and lymphocytic colitis in severe disease with autoimmune associations requiring colectomy: a case report. Gut 1996, 38(5):788-91.

10. Jawhari A, Talbot IC: Microscopic, lymphocytic and collagenous colitis. Histopathology 1996, 29(2):101-10.

11. Mosnier JF, Larvol L, Barge J, Dubois S, De La Bigne G, Hénin D, Cerf M: Lymphocytic and collagenous colitis: an immunohistochemical study. The American journal of gastroenterology 1996, 91(4):709-13.

12. Pardi DS, Smyrk TC, Tremaine WJ, Sandborn WJ: Microscopic colitis: a review. The American journal of gastroenterology 2002, 97(4):794-802.

13. Fernández-Bañares $F$, Salas A, Forné M, Esteve M, Espinós J, Viver JM: Incidence of collagenous and lymphocytic colitis: a 5-year populationbased study. The American journal of gastroenterology 1999, 94(2):418-23.

14. Olesen M, Eriksson S, Bohr J, Järnerot G, Tysk C: Microscopic colitis: a common diarrhoeal disease. An epidemiological study in Orebro, Sweden, 1993-1998. Gut 2004, 53(3):346-50.

15. Bohr J, Tysk C, Eriksson S, Järnerot G: Collagenous colitis in Orebro, Sweden, an epidemiological study 1984-1993. Gut 1995, 37(3):394-7.

16. Olesen M, Eriksson S, Bohr J, Järnerot G, Tysk C: Lymphocytic colitis: a retrospective clinical study of 199 Swedish patients. Gut 2004, 53(4):536-41.

17. Barta Z, Mekkel G, Csípo I, Tóth L, Szakáll S, Szabó GG, Bakó G, Szegedi G, Zeher M: Microscopic colitis: a retrospective study of clinical presentation in 53 patients. World journal of gastroenterology: WJG 2005, 11(9):1351-5.

18. Leigh C, Elahmady A, Mitros FA, Metcalf A, al-Jurf A: Collagenous colitis associated with chronic constipation. The American journal of surgical pathology 1993, 17(1):81-4.

19. Greenson JK, Stern RA, Carpenter SL, Barnett JL: The clinical significance of focal active colitis. Human pathology 1997, 28(6):729-33.

20. Volk EE, Shapiro BD, Easley KA, Goldblum JR: The clinical significance of a biopsy-based diagnosis of focal active colitis: a clinicopathologic study of 31 cases. Modern pathology: an official journal of the United States and Canadian Academy of Pathology, Inc 1998, 11(8):789-94.

21. Brown PI, Greenson JK: The clinical significance of focal active colitis in pediatric patients. The American journal of surgical pathology 2003, 27(8):1134-8.

22. Saito YA, Locke GR, Talley NJ, Zinsmeister AR, Fett SL, Melton LJ: A comparison of the Rome and Manning criteria for case identification in epidemiological investigations of irritable bowel syndrome. The American journal of gastroenterology 2000, 95(10):2816-24.

23. Balboa A, Mearin F, Badía X, Benavent J, Caballero AM, DomínguezMuñoz JE, Garrigues V, Piqué JM, Roset M, Cucala M, Figueras M: Impact of upper digestive symptoms in patients with irritable bowel syndrome. European journal of gastroenterology \& hepatology 2006, 18(12):1271-7.

24. Brandt LJ, Chey WD, Foxx-Orenstein AE, Schiller LR, Schoenfeld PS, Spiegel BM, Talley NJ, Quigley EM: An evidence-based position statement on the management of irritable bowel syndrome. American College of Gastroenterology Task Force on Irritable Bowel Syndrome. The American journal of gastroenterology 104(Suppl 1):S1-35.

25. Olden KW: Diagnosis of irritable bowel syndrome. Gastroenterology 2002, 122(6):1701-14.

26. Hahn B, Watson M, Yan S, Gunput D, Heuijerjans J: Irritable bowel syndrome symptom patterns: frequency, duration, and severity. Digestive diseases and sciences 1998, 43(12):2715-8.

27. Kao KT, Pedraza BA, McClune AC, Rios DA, Mao YQ, Zuch RH, Kanter MH, Wirio S, Conteas CN: Microscopic colitis: a large retrospective analysis from a health maintenance organization experience. World journal of gastroenterology: WJG 2009, 15(25):3122-7.

28. Chey WD, Nojkov B, Rubenstein JH, Dobhan RR, Greenson JK, Cash BD: The yield of colonoscopy in patients with non-constipated irritable bowel 
syndrome: results from a prospective, controlled US trial. The American journal of gastroenterology 2010, 105(4):859-65.

29. Limsui D, Pardi DS, Camilleri M, Loftus EV Jr, Kammer PP, Tremaine WJ, Sandborn WJ: Symptomatic overlap between irritable bowel syndrome and microscopic colitis. Inflammatory bowel diseases 2007, 13(2):175-81.

30. Yantiss RK, Odze RD: Optimal approach to obtaining mucosal biopsies for assessment of inflammatory disorders of the gastrointestinal tract. The American journal of gastroenterology 2009, 104(3):774-83.

31. Loftus EV: Microscopic colitis: epidemiology and treatment. The American journal of gastroenterology 2003, 98(12 Suppl):S31-6.

32. Tunçer C, Cindoruk M, Dursun A, Karakan T: Prevalence of microscopic colitis in patients with symptoms suggesting irritable bowel syndrome. Acta gastro-enterologica Belgica 2003, 66(2):133-6.

33. Driman DK, Preiksaitis HK: Colorectal inflammation and increased cell proliferation associated with oral sodium phosphate bowel preparation solution. Human pathology 1998, 29(9):972-8.

34. Lee FD: Drug-related pathological lesions of the intestinal tract. Histopathology 1994, 25(4):303-8.

35. Wong NA, Penman ID, Campbell S, Lessells AM: Microscopic focal cryptitis associated with sodium phosphate bowel preparation. Histopathology 2000, 36(5):476-8.

36. Zwas FR, Cirillo NW, el-Serag HB, Eisen RN: Colonic mucosal abnormalities associated with oral sodium phosphate solution. Gastrointestinal endoscopy 1996, 43(5):463-6.

\section{Pre-publication history}

The pre-publication history for this paper can be accessed here: http://www.biomedcentral.com/1471-230X/11/96/prepub

doi:10.1186/1471-230X-11-96

Cite this article as: Ozdil et al:: The frequency of microscopic and focal active colitis in patients with irritable bowel syndrome. BMC

Gastroenterology 2011 11:96.

\section{Submit your next manuscript to BioMed Central and take full advantage of:}

- Convenient online submission

- Thorough peer review

- No space constraints or color figure charges

- Immediate publication on acceptance

- Inclusion in PubMed, CAS, Scopus and Google Scholar

- Research which is freely available for redistribution

Submit your manuscript at www.biomedcentral.com/submit 